\title{
Behavioral Problems in Adolescents Raised by Their Grandparents
}

\author{
Isabel $\mathrm{M}^{\mathrm{a}}$ Bernedo, María Jesús Fuentes, and Milagros Fernández \\ Universidad de Málaga (Spain)
}

\begin{abstract}
This research analyzes, for the first time using a Spanish sample, the behavioral problems of adolescents in the custody of their grandparents. The sample consisted of 68 adolescents ( 31 boys and 37 girls, with a mean age of 13.7 years) in the custody of 54 grandparents with an average age of 65.9 years for the grandfathers, and 63.6 years for the grandmothers. The instrument employed was the Child Behavior Checklist (CBCL; Achenbach, 2001). The results indicate that the majority of both boys and girls can be classified within the normal range on scales of internal behavior, external behavior and total behavioral problems. When gender and age differences were analyzed, it was found that boys had more behavioral problems than girls on scales of incompliance with rules and external behavior. Meanwhile, it was shown that older adolescents had more somatic problems, as well as more behavioral problems, as measured by both the internal scale and total scale of the CBCL, than the younger participants.

Keywords: behavioral problems, grandparents, adolescent grandchildren, family custody
\end{abstract}

Este trabajo recoge, por primera vez en población española, la incidencia de los problemas de conducta presentados por los adolescentes acogidos por sus abuelos. Este estudio analiza a 68 adolescentes ( 31 chicos y 37 chicas, con una media de edad de 13,7 años) acogidos por 54 abuelos/as, con una media de edad de 65,9 años para los abuelos y de 63,6 años para las abuelas. El instrumento utilizado fue el Child Behaviour Checklist (CBCL, Achenbach, 2001). Los resultados indican que tanto la mayoría de los chicos como de las chicas se encuentran en el rango de normalidad en las escalas de internalización, externalización y total en problemas de conducta. Al analizar las diferencias de sexo y edad, se encontró que los chicos presentan más problemas de conducta en incumplimiento de normas y en la escala de externalización, que las chicas, y que los adolescentes mayores presentan más problemas somáticos, y más problemas de conducta en la escala de internalización y en el total del CBCL, que los menores.

Palabras clave: Problemas de conducta, abuelos, nietos adolescentes, acogimiento familiar.

This study is part of a project by the Ministry of Sciences and Technology (MSAT) (General Director of Research) (SEJ2004-03426/EDUC) and is co-financed by the FEDER fund. Access to the families and information about the adolescents' custody was obtained in collaboration with Infant Protection Services and Families of the Provincial Delegation for Equality and Social Well-being of Malaga (Government of Andalusia).

Correspondence concerning this article should be addressed to Isabel $\mathrm{M}^{\mathrm{a}}$ Bernedo Muñoz, Facultad de Psicología, Universidad de Málaga, Campus de Teatinos, 29071-Málaga, España. E-mail: bernedo@uma.es

How to cite the authors of this article: Bernedo, I.M., Fuentes, M.J. and Fernández, M. 
Child custody by members of the extended family is the most frequent type used in our country. The primary motive behind the extensive use of this kind of protection most likely reflects compliance with leading legislation on the matter, given that Law 21/November 11, 1987 indicates that custody of a minor should be procured within their own family environment. Nevertheless, it is possible that other variables arise that influence professional practice and implementation of this law such as, for example, the favorable predisposition of relatives to care for children when their parents are unable to do so, the small professional force and economic expense they dedicate to care-giving, at least until now, and the very slight educational demand on the family's guardians, etc. (Amorós \& Palacios, 2004).

Although the legislation shows the importance of the extended family in child-rearing and establishes that it should be the first option to professionals in cases of child neglect or desertion, very few studies have been carried out in our country on the subject (Bernedo, 2004; Fernández del Valle, Álvarez-Baz \& Bravo, 2002; Lumbreras, Fuentes, \& Bernedo, 2005; Villalba \& Sánchez, 2000).

At the international level, research on the subject of family custody (Iglehart, 1994; Marchand \& Meulenbergs, 1999) has highlighted a series of advantages and disadvantages associated with this way of raising a child.

Among the prime advantages are the following: (a) it allows the child to remain in their usual environment with people they already know, avoiding the uprooting effect of internment in a center, and facilitating contact with parents and siblings (Beeman, Kim, \& Bullerdick, 2000; Kolomer, 2000); (b) it favors the formation of the child's identity, fortifying it with a sense of the continuity of their family as well as cultural history (Keefer \& Shooler, 2000); (c) it contributes to the affective stability of the child by diminishing their sense of family loss (Berrick, 1998); and (d) it reduces the probability that the children be placed in orphanages, children's homes or other types of care since the majority of these children go directly from living with their parents to being raised by relatives (Beeman et al, 2000; Iglehart, 1994).

The following are considered to be among the principal disadvantages (Gibbs \& Müller, 2000; Marchand \& Meulenbergs, 1999): (a) when the guardians are grandparents, intergenerational conflicts are greater than in other families, especially when the grandchildren reach adolescence (Sánchez, 2000); (b) Relatives may feel pressured to take custody of the children so that they remain within the family; (c) the family care-givers have a lower educational level and have access to fewer economic resources than other types of care-givers, conditions which could worsen the child's situation, and many grandmothers reduce their hours at work or abandon them altogether in order to care for the child (Caputo, 2001); and (d) these guardians do not follow the educational and advising processes that are demanded of other guardians and they receive scarce economic support (Fernández del Valle et al., 2002).
These difficulties could affect the child's development, so it makes sense to examine how these children adapt so as to evaluate the extent to which the advantages of this type of child guardianship compensates for the inconveniences it could possibly bring. Along those lines, the present study aims to analyze the adaptation of children raised by family members, as well as the incidence of behavioral problems present in said group.

A bibliographic review of studies on behavioral problems in adolescents raised by their relatives, evaluated using the Child Behavior Checklist (CBCL; Achenbach, 2001), has revealed two types of research studies: those that analyze the behavioural problems of adolescents raised by members of their extended family, and those that compare them either to cases of adolescents adopted or placed in foster care with a family apart from their own, or that compares them to the general population. The principal results are presented below.

The objective of the Starr, Dubowitz, Harrington, and Feigelman study (1999) was to understand the behavioral problems of 66 adolescents raised by relatives first from the point of view of the guardians, from the perspective of the adolescents themselves and also from the perspective of their teachers. The CBCL, the Youth Self Report (YSR) and certain items appearing in both were used to measure the teachers' opinions. From the perspective of the guardians, the adolescents had significantly more external problems (aggressive behavior and incompliance with rules), as well as more attentional problems, than was reported by the adolescents themselves. The guardians and adolescents alike reported somatic problems and aggressive behavior.

Due to the lack of studies specifically centered on the analysis of behavioral problems manifested in adolescents who are raised by their relatives, the results of some studies follow which compare these adolescents with others that may or may not still be in the custody of those guardians.

When different studies are compared (Everett, 1995; Shore, Sim, Le Prohn, \& Keller, 2002), certain discrepancies in their results surface that relate to the behavioral problems of minors in the custody of members of their extended family. Some studies (Dubowitz, Feigelman, Harrington, Starr, Zuravin, \& Sawyer, 1994; Dubowitz, Zuravin, Starr, Feigelman, \& Harrington, 1993) have found that minors raised by extended family members exhibit more behavioural problems than those not raised by members of the extended family while Keller, Wetherbee, Le Prohn, Payne, Sim, and Lamont (2001) found that they actually exhibit fewer problems of this kind. However, when children raised by members of their own extended family are compared with those raised in foster care or who were adopted by a different family, all of the studies in this review have found that minors raised by their own relatives present fewer behavioural problems than those raised by some other family (Heflinger, Simpkins, \& Combs-Orme, 2000; Iglehart, 1994; Keller et al., 2001; Landsverk, Davis, Ganger, Newton, \& Johnson, 1996; Starr et al., 1999). 
Dubowitz et al. (1993) studied what variables elicit an influence on how behavioral problems manifest themselves in a sample of 346 children in the custody of their relatives using the CBCL. The variables that were found to be significantly associated with those problems were: the motives behind the parental abandonment, the child's sex, the minor's age and the educational level of their guardians. Later, Dubowitz et al. (1994) evaluated the behavioral problems of 288 children raised by members of their extended families between the ages of 4 and 18 years old within the same sample. These results coincided with those of a previous study. The adolescents who were raised by members of their extended families exhibited more behavioral problems than those who were not. The scales on which the adolescents scored highest were: delinquent behavior, aggressive behavior, problems of attention, and social problems.

Keller et al. (2001) conducted a study with 240 adolescents between the ages of 4 and 18 years (110 boys and 130 girls), $28 \%$ of whom were in the custody of relatives and $72 \%$ were not. Upon analyzing their behavioral problems using the CBCL, the results showed that children who were raised by their relatives exhibited better social competency and have fewer behavioral problems (internal as well as external) than those who were not raised by relatives. Through a multivariate analysis, bearing in mind the subjects' type of guardian, race and sex, it was confirmed that children raised by their relatives exhibited fewer behavioral, social, thought and attentional problems than those who were raised in isolation by non-family members. In a comparison later carried out with the general population, fewer behavioral problems were found among minors raised by their relatives.

Landsverk (1996) used the CBCL to compare the behavioral problems of minors in the custody of extended family members as opposed to being in the custody of a different family. The sample was comprised of 669 children between the ages of 2 and 16 years old. They found that children in the custody of extended family exhibited fewer problems (emotional, behavioral, developmental, learning and physical) and had a lower probability of having various problems at the same time, than those who were raised by a different family.

Iglehart (1994) also found significant differences in the behavioral problems present in adolescents raised by their relatives (332) and those raised by non-family members (638). Thirty-eight percent were boys and 62\% were girls. The adolescents raised by their relatives had fewer behavioral problems, better emotional stability and higher functioning in mental health than those who were not.

The Heflinger et al. (2000) study collected data using the CBCL from 311 children and adolescents 91 of which were under the custody of members of their extended family, 126 of which were under the care of a different family and 94 of which lived in an orphanage or children's home. Their results showed that the children in the care of their own families had a higher probability of being in the non-clinical range for internal behavioral problems (80\%) as compared with the children under the custody of foster parents or adoptive parents $(77 \%)$ or those living in an orphanage or children's home $(61 \%)$. Also, the minors situated within the clinical range exhibited more problems of the external kind (23\%) than of the internal kind (19\%). The scales on which children raised by their relatives showed greater difficulty were: aggression, delinquency, isolation, somatic problems and anxiety-depression.

Shore et al. (2002) conducted a study of 185 teachers of 129 minors in foster care or in the care of an adoptive family, and 56 in the care of members of their extended family. Once the data were collected, they were compared with the data provided by care-givers in a study by Keller et al. (2001). Teachers and guardians filled out the Teachers' Report Form (TRF) and the Child Behavior Checklist (CBCL), respectively. The results expressed a high level of agreement between the children's guardians and their teachers. Upon comparing the extended and foster families/adoptive families with the general population, the following was found: (a) minors raised by their extended families presented more external problems and more delinquent behavior than did the general population; and (b) the minors under foster care or in the care of an adoptive family had more problems on the external scale and on the total scale of the CBCL, and more anxiety-depression problems, problems of attention and aggressive behavior than was found in the general population. In comparing minors in the custody of their own families to those in foster or adoptive care, it was found that the former had higher scores on the subscale of delinquent behavior than the latter. In spite of that fact, the authors concluded that, generally speaking, minors raised by their extended families exhibit fewer problems than those raised in foster or adoptive care.

To synthesis the conclusions of the majority of the above mentioned studies, it may be said that adolescents raised by their relatives exhibit fewer behavioral problems than those who are raised by a foster or adoptive family, but that in either case, more behavioral problems occur than in the general population.

This global affirmation requires certain specifications, especially when the age and sex of the adolescents is taken into consideration. The results most relevant to those two variables follow.

In some studies of custody by the extended family, and in others that compare the extended families with foster or adoptive families (Dubowitz et al., 1994; Keller et al., 2001), it was found that boys exhibited more behavioral problems than girls, but in a study by Heflinger et al. (2002), that difference was not found.

In the Keller et al. (2001) study, the boys exhibited more behavioral problems than the girls and the girls' problems were more often internal than external. The data from a study by Starr et al. (1999), of 66 adolescents in the custody of members of their extended families, also indicated that 
the boys had more problems considered to be within the clinical range than did the girls.

From the care-givers' point of view, the boys presented more internal, social, thought, attentional and somatic problems than the girls did. On the other hand, from the adolescents' own point of view, the boys had more behavioral problems, more problems with their shelter/protection, and more somatic problems than the girls did across the entirety of the sample.

With regards to age, some studies have found that minors exhibit more behavioral problems during the intermediate period of adolescence (12-15 years old) (Heflinger et al., 2002), while others have found that those behavioral problems increase with age (Dubowitz et al., 1994). In the study by Dubowitz et al. (1994) the results demonstrated that boys have more behavioral problems than girls and that those problems usually increase with age and that did not occur among the girls. The behavioral problems that the boys exhibited were equally external and internal issues.

Although the results of research on behavioral problems in boys and girls do not completely coincide, the majority of studies have concluded that boys exhibit more behavioral problems, particularly of an external nature, than girls, especially when they reach their final years of adolescence.

In addition to sex and age, the relationship between certain variables in the personal history of the child who was raised or adopted and their behavioral problems have been studied. The following are found to be the primary variables associated with behavioral problems: (a) if the child has suffered active abuse (Bryson \& Caspar, 1999; Sánchez, 2000), (b) if the parents were substance abusers (Benedict, Zuravin, \& Stallings, 1996; Burnette, 1999; Johnson, 2002; Shapiro, Shapiro \& Paret, 2001), (c) if the parents were mentally ill (Benedict et al., 1996; Ge et al., 1996), (d) if the parents were incarcerated (Phillips \& Bloom, 1998; Seymour, 1998), (e) if the child stayed for a prolonged time in an orphanage or children's home (Pinderhughes, 1998), and (f) if the child entered into alternative custody at a late age (Brodzinsky, 1990; Fuentes, Fernández, \& Bernedo, 2004; Verhulst, Althaus, \& Versluis-Den Bieman, 1990).

The present study tries to approach an understanding of the actual situation of adolescents raised by their relatives. In order to do so, the following objectives have been taken into consideration: to analyze the incidence of behavioral problems among adolescents raised by their grandparents; the most frequent type of problem encountered; the severity of the problems or their classification in the clinical range; and to find out whether age, sex or other variables in the personal history of the adolescent are associated with behavioral problems.

With the proposed objectives in mind and a bibliographic base on the subject provided above, the following hypotheses have been formed: (1) it is expected that the majority of the adolescents in the study will fall within the normal range on the CBCL; (2) that the boys will score higher on measures of external problems than the girls will; (3) that the older adolescents will have more behavioral problems than the younger ones; and (4) that some variables from the personal history of the children, such as having suffered active abuse, having had parents who were substance abusers or having stayed for a prolonged time in an orphanage or children's home will be associated with high scores on measures of behavioral problems.

\section{Method}

\section{Subjects}

Characteristics of the adolescents. The sample of adolescents was composed of 68 subjects: 37 girls and 31 boys. The average age at the time the data was collected was 13.7 years old $(S D=1.8)$, ranging from 11 to 17 years old. The minors were placed in the custody of their grandparents at the age of 1.3 years old, on average $(S D=$ 2.2), ranging from 0 to 13 years.

According to data provided by Infant and Family Protection Services, 43 of the minors $(61.4 \%)$ had not been placed in orphanages or children's homes prior, while 27 children (38.6\%) had been, but only in one. None of them had previously been in a situation where a relative was care-giver that did not work out. $95.8 \%$ of the children had been victims of some type of abuse by their parents and $4.2 \%$ had not. Of those who suffered abuse, $82.9 \%$ of the children suffered a form of passive abuse (abandonment, neglect, etc.), while $12.9 \%$ additionally suffered active abuse (physical or emotional).

Characteristics of the grandparent care-givers. The number of families studied was 54 , which is less than the number of adolescents studied due to the fact that in 12 cases, the grandparents had taken custody of multiple siblings. Forty-two grandparents (77.8\%) had taken custody of only one child, $9(16.7 \%)$ had taken custody of 2,2 $(3.7 \%)$ of 3 and $1(1.9 \%)$ of five children. Some, however, were not included in the sample because they were not within the adolescent age range.

Of the 54 grandparents, $36(66.7 \%)$ were their child's maternal grandparent and $18(33.3 \%)$ were paternal grandparents. The average age of the grandfather guardians was 65.9 years old $(S D=8.1)$, ranging from 45 to 82 years old, while the average age of the grandmothers was 63.6 years old $(S D=7.6)$, ranging from 52 to 82 years old. The average age of the grandfathers at the time they were given custody was 53.7 years old $(S D=8.3)$, ranging from 33 to 73 years old, and for the grandmothers it was 50.9 years old $(S D=7.3)$, ranging from 40 to 71 years old.

In 49 cases (90.7), it was the grandparents who took the initiative to take custody of their grandchildren, while in only 5 cases $(9.3 \%)$, it was Infant and Family Protection Services that proposed that the grandparents care for their grandchildren. 
The reasons why the grandparents took custody of their grandkids were the following: (a) substance abuse on the part of the parents (35 cases), (b) the parents disappeared (19 cases), (c) the children were physically abused (9 cases), (d) the parents were incarcerated (7 cases), (e) the parents were mentally ill (4 cases), and (f) the parents died (3 cases). In some cases, multiple reasons applied.

\section{Process}

In order to find out how many children are in the custody of members of their extended family in the province of Málaga, Spain, in June of 2001, a list of such cases was solicited to the Infant and Family Protection Services from the Provincial Delegation for Equality and Social Well-being of Málaga (Government of Andalucía). This organization had facilitated the cases of a total of 360 minors that by that date were in the custody of members of their extended family.

In order to compose the sample, the following characteristics were taken into account: (1) that the caregivers were grandparents and not aunts or uncles of the minors, in order to eliminate the influence of generational differences on the education of the adolescents; (2) that the time spent in the custody of these family members was greater than one year, such that the minors would have already have adapted to the family; (3) that at the time the data was collected, the subjects were adolescents (between 11 and 17 years of age); and (4) that the adolescents did not suffer from serious physical, psychological or sensory impairment.

Of the 360 cases mentioned above, 292 were eliminated for the following reasons: 9 of the adolescents had returned to live with their biological parents; in 128 cases, the minors did not fall within the requisite age range; 88 adolescents were being raised by relatives that were not their grandparents: 69 by their aunts or uncles and 19 by their siblings; 65 were discounted for other reasons (because at that time, their cases had already been closed; at the time the data was collected, the adolescents were in the midst of judicial process, so their information was not accessible in the Infancy and Family Protection records; or because the families were not able to be found at the time the study was conducted), and in 2 cases, the CBCL could not be administered because the participants were not of the CBCL's requisite age, but data was still collected for their siblings and the other subjects that participated in the study.

We established contact with the 54 grandparents that met the aforementioned requirements accessing either their phone numbers in the minors' records with the Infant and Family Protection Services, through certified mail or by visiting their homes. Once contact had been established, the guardians were informed of the reason for the visit, of the general characteristics of the information collection process (type of tests, to whom they would be directed, how much time participation would require of them, etc.) and the identities of the people who would be interviewing them. Next, the dates were set for when they would meet for the interview and the location was set to be the grandparents' homes. All 54 grandparents accepted the offer to participate in the study. During the visits to the grandparents' homes, the researchers first confirmed the information from the case files and the adolescents' personal history. Then, they filled out the (CBCL) in the researchers' presence.

\section{Instrument}

The Child Behavior Checklist (CBCL/11-18; Achenbach, 2001 ) is part of a multiaxial system of evaluation called the Achenbach Empirical Evaluation System (ASEBA) (Achenbach, 1991). The system consists of one scale of interior behaviors, another for exterior behaviours; a total score is also taken for total behavioural problems (Keller et al., 2001). The internal scale is composed of three subscales: social rejection or isolation (9 items) (they like being alone more than with others or they do not like to speak), somatic problems (10 items) (they are prone to nausea or they are always tired), and anxiety and depression (13 items) (they complain of feeling lonely or they cry often). The external scale consists of two subscales: incompliance with rules (13 items) (they do not seem to feel guilty when they misbehave or they destroy things) and aggressive behaviour (20 items) (they argue a lot or they destroy their own belongings). The test has three response choices: false or rarely (0), in part or sometimes (1), and definitely or almost always (2). Also, this test allowed us to identify whether subjects were in the clinical or normal range, or whether they were on the border of the two, by considering the scores as a function of the boys and girls' sex and age (Achenbach, 2001; Keller et al., 2001).

The data for the reliability and validity of the CBCL are the following. The Cronbach alpha value for the internal scale is $0.90,0.94$ for the external scale, and 0.97 for the Total on the test. The validity of the CBCL found using the BASC (Reynolds \& Kamphaus, 1992) is 0.83 for the internal scale, 0.88 for the external scale and 0.89 for the Total of the test $(p<.001)$.

The version of the CBCL used was translated to Spanish by the Epidemiological and Diagnostic Group in Developmental Pychopathology of the Universitat Autónoma de Barcelona, Spain. It was tested using comparable, Spanish samples, and those results were figured into the present version of the test.

The Cronbach alpha for this study's sample is 0.88 for the internal scale, 0.93 for the external scale and 0.89 , for the total on the CBCL test. The data surrounding the grandparent guardians, the reasons behind their taking custody of the minors and the adolescents' history found in the children's files with the Infant and Family Protection Services were later confirmed during the subsequent visits to the grandparent guardians' homes. 
Results

\section{The Boys' Behavioural Problems}

In Table 1 the descriptive statistics are shown for the five subscales of the CBCL (isolation/social rejection, somatic problems, anxiety/depression, incompliance with rules/rule breaking, and aggressive behaviour), and for the internal scale, external scale, and the total of the CBCLversion for boys.

The coefficients of skewness and kurtosis indicate that the distributions do not stray substantially from normality. However, it is important to note as well that the scales of aggression and external behavior do, in fact, stray moderately from normality, while stilling falling within the acceptable range.

Listed in Figure 1, the percentage of boys in the normal range, the clinical ranges, and on the border of the two on the internal, external, and total scales of the CBCL appear. It may be seen that the majority of the boys fall within the normal range in the three abovementioned scales. On the internal scale, 17 (54.8\%) fall within the normal range, 3 $(9.7 \%)$ on the border and $11(35.5 \%)$ in the clinical range. On the total scale of the CBCL (internal and external), 26 boys $(83.9 \%)$ fall within the normal range, $3(9.7 \%)$ on the border and $2(6.5 \%)$ in the clinical range.

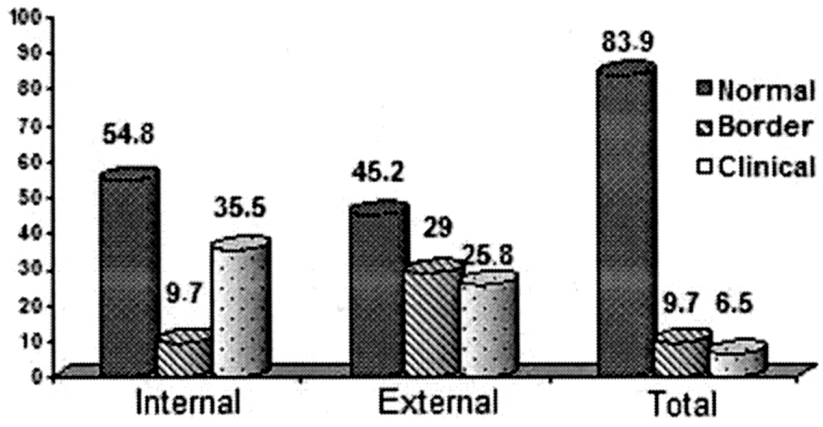

Figure 1. Percentage of male adolescents in the normal range, clinical range, and on the border of the two on internal, external and CBCL total scales.

\section{The Girls' Behavioural Problems}

In Table 2, the descriptive statistics are shown for the five subscales of the CBCL (isolation/social rejection, somatic problems, anxiety/depression, incompliance with rules/rule breaking and aggressive behaviour), and for the internal scale, external scale, and the total of the CBCL-version for girls. The coefficients of skewness and kurtosis indicate that the distributions do not stray substantially from normality.

Table 1

Mean, standard deviation (SD), minimum and maximum of the scores on scales and subscales of behavioural problems on the $C B C L$-version for boys*

\begin{tabular}{lcccccccc}
\hline & Isolati & Som prob & Anxie/Depres & Rule breaki & Agress & Internal Scale & External Scale & Total Scale \\
\hline $\mathrm{N}$ & 31 & 31 & 31 & 31 & 31 & 31 & 31 & 31 \\
Mean & 4.35 & 1.29 & 4.97 & 5.58 & 9.55 & 10.61 & 15.13 & 25.74 \\
$\mathrm{SD}$ & 3.22 & 1.57 & 4.19 & 5.95 & 7.61 & 6.30 & 12.80 & 17.34 \\
$\mathrm{Min}$ & 0 & 0 & 0 & 0 & 0 & 0 & 0 & 3 \\
Max & 11 & 6 & 17 & 24 & 31 & 27 & 53 & 1.43 \\
Skew & 0.17 & 1.23 & 1.17 & 1.53 & 1.17 & 0.53 & 1.15 \\
Kurtos & -0.97 & 1.14 & 1.50 & 2.18 & 1.62 & 0.04 & 2.40 \\
\hline
\end{tabular}

*Note: Isolati = Isolation; Som prob = Somatic problems; Anxie/Depres = Anxiety/Depression; Rule breaki = Rule breaking; Agress = Aggression and Internal/external/total scales $=$ Scales of the CBCL.

Table 2

Mean, standard deviation (SD), minimum and maximum of the scores on scales and subscales of behavioural problems on the CBCL-version for girls*

\begin{tabular}{lcccccccc}
\hline & Isolati & Som prob & Anxie/Depres & Rule breaki & Agress & Internal Scale & External Scale & Total Scale \\
\hline $\mathrm{N}$ & 37 & 37 & 37 & 37 & 37 & 37 & 37 & 37 \\
Mean & 3.95 & 1.43 & 5.51 & 2.16 & 7.32 & 10.65 & 9.76 & 20.40 \\
$\mathrm{SD}$ & 3.37 & 1.64 & 3.02 & 2.59 & 5.72 & 6.10 & 7.17 & 11.30 \\
$\mathrm{Min}$ & 0 & 0 & 0 & 0 & 0 & 0 & 0 & 1 \\
Max & 12 & 6 & 13 & 9 & 22 & 25 & 25 & 44 \\
Skew & 0.88 & 1.00 & 0.71 & 1.35 & 0.70 & 0.27 & 0.54 & 0.57 \\
Kurtos & 0.01 & 0.075 & 0.68 & 1.29 & -0.51 & -0.34 & -0.97 & -0.70 \\
\hline
\end{tabular}

*Note: Isolati = Isolation; Som prob = Somatic problems; Anxie/Depres = Anxiety/Depression; Rule breaki = Rule breaking; Agress = Aggression and Internal/external/total scales $=$ Scales of the CBCL. 
The percentages of girls in the normal and clinical ranges, and on the border of the two, on the internal, external, and total scales of the CBCL are listed in Figure 2. It is clear that the majority of the girls fall within the normal range on all three scales. It is particularly noteworthy that not one of them falls within the clinical range on the total scale of the CBCL. On the internal scale, $22(59.5 \%)$ fall within the normal range, $6(16.2 \%)$ fall on the border and $9(24.3 \%)$ in the clinical range. On the external scale, $23(62.2 \%)$ are in the normal range, $4(10.8 \%)$ on the border and $10(27 \%)$ in the clinical range. On the total scale of the CBCL (both internal and external), 32 girls (86.5\%) fall within the normal range, 5 $(13.5 \%)$ on the border and none fall within the clinical range.

\section{Differences in Adolescent Behavioral Problems according to Sex and Age}

The Levene test was applied in order to test the homogeneity of the variance. In Table 3, the statistics for the Levene contrast are shown, revealing that only the value for the incompliance with rules subscale, a subscale of the external scale, was significant $(p=.002)$, which breaks the condition of homogeneity of variance. In any case, the contrast in the ANOVA may be considered robust, given that the sizes of the groups are similar, and that the distributions of the variables are considered normal.

Table 3

Levene contrast and equality of variance

\begin{tabular}{lcc}
\hline \multicolumn{1}{c}{ CBCL } & $\mathrm{F}(3.64)$ & $\mathrm{p}$ \\
\hline Isolation & .897 & .448 \\
Somatic Problems & 2.766 & .050 \\
Anxiety and Depression & 1.593 & .200 \\
Rule breaking & 5.750 & .002 \\
Aggression & 1.197 & .318 \\
Total internal & .969 & .413 \\
Total external & 2.081 & .111 \\
Total CBCL & 1.928 & .134 \\
\hline
\end{tabular}

A two factor ANOVA was done in order to understand the influence of the sex and age of adolescents on their scores on different scales and subscales of the CBCL. Table 4 displays the results found and also includes the Eta coefficient to show the quantity of said differences. The data surrounding the interaction between sex and age was not significant in any of the scales or subscales. Thus, it was affirmed that the effects of sex and age on behavioral problems (CBCL) are independent. In Table 4 the effects of age and sex on their scores on the scales and subscales of the CBCL are displayed, age on one side and sex on the other.

Due to the study's relatively small sample size, a greater effect would have been needed to demonstrate statistical significance. For that reason, it was found that the Eta coefficient - here shown squared - was an absolute indication of the robustness of the effect. To analyze the size of the effect contributes valuable information to that obtained from the $p$ values since sample size had been factored into $p$. As can be seen in Table 4, in cases where statistically significant effects are involved, the associated value of Eta squared exceeds 0.06, which equates to an effect of $6 \%$, or to a correlation of approximately 0.25 . Thus, quantities less than that value, such as a value of Eta squared of 0.04 , could be considered relevant effects even though they do not qualify as being of statistical significance.

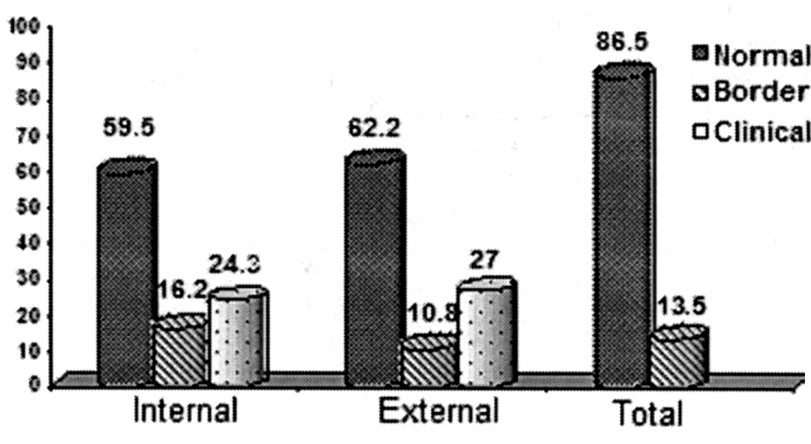

Figure 2. Percentage of female adolescents in the normal range, the clinical range, and on the border of the two on the internal, external and CBCL total scales.

Table 4

Two factor analysis of variance (age, sex and age*sex)

\begin{tabular}{|c|c|c|c|c|c|c|c|c|c|c|c|c|c|}
\hline \multirow[t]{2}{*}{ CBC } & \multirow[b]{2}{*}{$\mathrm{N}$} & \multicolumn{4}{|c|}{ AGE } & \multicolumn{4}{|c|}{ SEX } & \multicolumn{4}{|c|}{ AGE*SEX } \\
\hline & & $F(1.68)$ & $\mathrm{P}$ & eta $^{2}$ & Robust & $\mathrm{F}(1.68)$ & $\mathrm{p}$ & $\mathrm{eta}^{2}$ & Robust & $\mathrm{F}(1.68)$ & $\mathrm{p}$ & eta $^{2}$ & Robust \\
\hline Isolation & 68 & 1.148 & .288 & .018 & .184 & .293 & .590 & .005 & .083 & .639 & .427 & .010 & .124 \\
\hline Somatic prob & 68 & 4.600 & .036 & .067 & .561 & .097 & .757 & .002 & .061 & .831 & .366 & .013 & .146 \\
\hline Anxiety/Depress & 68 & 1.387 & .243 & .021 & .213 & .341 & .561 & .005 & .089 & .430 & .514 & .007 & .099 \\
\hline Rule breaking & 68 & 3.735 & .058 & .055 & .478 & 10.604 & .002 & .142 & .894 & .007 & .933 & .000 & .051 \\
\hline Aggression & 68 & 2.052 & .157 & .031 & .292 & 2.064 & .156 & .031 & .293 & 1.893 & .174 & .029 & .273 \\
\hline Internal & 68 & 3.995 & .050 & .059 & .503 & .001 & .971 & .000 & .050 & .176 & .676 & .003 & .070 \\
\hline External & 68 & 2.796 & .099 & .042 & .377 & 5.084 & .028 & .074 & .603 & .959 & .331 & .015 & .161 \\
\hline Total CBCL & 68 & 4.221 & .044 & .062 & .525 & 2.622 & .110 & .039 & .358 & .771 & .383 & .012 & .139 \\
\hline
\end{tabular}


Bearing in mind the means for each of the scales and subscales of the CBCL as a function of sex (boys or girls) and age (younger vs. older than 13 years old) (Table 5), and the results of the two factor ANOVA (Table 4), the data show that girls have fewer problems than boys on the incompliance with rules subscale and on the external scale. On the other hand, it is also evident that younger adolescents exhibit fewer behavioral problems than the older ones on the somatic problems subscale, on the internal scale and on the scale of total behavioral problems.

\section{Behavioral Problems and Variables Related to Adolescents' Personal History}

No relationship was found between the manifestation of behavioral problems and the following variables related to the adolescents' personal history: having suffered active abuse, having stayed in orphanages or children's homes before, or the time spent in said centers. On the other hand, as Table 6 indicates, a relationship was found between substance abuse by the mother and the subscales of incompliance with rules and aggression, as well as the CBCL external and total scales. According to the grandparents, adolescents whose mothers were substance abusers break the rules more often $\left(t_{(64)}=-3.04, p<.01\right)$ and are more aggressive $\left(t_{(64)}=-2.16, p<.05\right)$ than the adolescents whose mothers were not. The adolescents whose mothers were substance abusers also had higher scores on the external scale $\left(t_{(64)}=-2.63, p \leq .01\right)$ and on the CBCL total scale $\left(t_{(64)}=-2.35, p<.05\right)$ than the adolescents whose mothers were not.

\section{Discussion}

One objective of the present study was to analyze the most frequent types of problems exhibited by adolescents who are raised by their grandparents. By understanding the descriptive statistics of the five subscales evaluated by the CBCL in boys and girls, it was found that the highest scores, on average, on areas of behavioral problems in male adolescents correspond to the subscales of incompliance with rules, aggression and anxiety/depression, and to the external scale. On the other hand, the girls scored highest on the subscales of aggression, anxiety/depression, and on the internal scale, which coincides with the results of the Keller et al. study (2001).

Upon analyzing the incidence of behavioral problems in adolescents raised by their grandparents, it was found that,

Table 5

Mean and SD for each of the scales and subscales of the CBCL according to sex and age

\begin{tabular}{lccccccc}
\hline CBCL & \multicolumn{2}{c}{ BOYS N $=31$} & \multicolumn{2}{c}{ GIRLS N $=37$} & \multicolumn{2}{c}{ YOUNGER N = 34 } & \multicolumn{2}{c}{ OLDER N = 34 } \\
& Mean & SD & Mean & SD & Mean & SD & Mean \\
\hline Isolation & 4.35 & 3.22 & 3.94 & 3.36 & 3.73 & 3.35 & 4.53 \\
Somatic Problems & 1.29 & 1.57 & 1.43 & 1.64 & 0.94 & 1.23 & 1.79 \\
Anxiety/Depression & 4.96 & 4.19 & 5.51 & 3.02 & 4.76 & 3.05 & 5.76 \\
Rule Breaking & 5.58 & 5.95 & 2.16 & 2.59 & 2.73 & 4.00 & 4.70 \\
Aggression & 9.55 & 7.60 & 7.32 & 5.72 & 7.32 & 5.92 & 9.35 \\
Total Internal & 10.61 & 6.30 & 10.65 & 6.10 & 9.17 & 5.36 & 12.09 \\
Total External & 15.13 & 12.80 & 9.75 & 7.16 & 10.35 & 8.62 & 14.06 \\
Total CBCL & 25.74 & 17.34 & 20.40 & 11.30 & 19.53 & 11.21 & 26.15 \\
\hline
\end{tabular}

Table 6

Relationship between mothers' substance abuse and the adolescents'scores on the subscales of incompliance with rules and aggression, and the external and total scales of the $C B C L$

\begin{tabular}{lcccccc}
\hline & \multicolumn{5}{c}{ MOTHERS' SUBSTANCE ABUSE } & \multicolumn{2}{c}{ NO (n=27) } & \\
CBCL & Mean & $(\mathrm{SD})$ & Mean & $(\mathrm{SD})$ & \\
\hline Incompliance with rules & 5.08 & 5.49 & 1.67 & 2.29 & $-3.04 * *$ \\
Aggression & 9.79 & 7.33 & 6.26 & 5.13 & $-2.16^{*}$ \\
External scale & 14.87 & 11.90 & 8.30 & 6.14 & $-2.63^{* *}$ \\
Total CBCL & 26.02 & 16 & 17.81 & 10.28 & $-2.35^{*}$ \\
\hline
\end{tabular}

$* \mathrm{p}<.05 ; * * \mathrm{p} \leq .01$ 
as the first hypothesis predicted, the majority of the adolescents in the study fall within the normal range on the internal, external and total scales of the CBCL. This result supports the findings of Heflinger et al. (2000) in that the adolescents being raised by members of the extended family had a higher probability of being in the normal range for behavioral problems than those who were raised in foster care, by adoptive families, or in an orphanage or children's home. The results of the present study show that a low percentage of subjects had behavioral problems classified within the clinical range, which supports the idea that adolescents raised by their grandparents tend toward normalcy. This is at least the case when research samples are composed of non-clinical participants, as was the case in this study.

The results of the present study confirm the data obtained by prior research studies with respect to the relationship between behavioral problems and variables such as the sex and age of the adolescent participants. Regarding the variable of sex, the boys had more external, behavioral problems than the girls, as the second hypothesis predicted. From the point of view of the grandparent guardians, the boys exhibited more external problems and incompliance with rules than did the girls. Some studies of extended family custody (Dubowitz et al., 1994; Keller et al., 2001) likewise found that boys had more behavioral problems than girls.

With regards to age, the older adolescents exhibited more problems in general than the younger ones, as our third hypothesis stated. It was confirmed that with age, adolescents score higher on the incompliance with rules subscale as well as on the scale of total behavioral problems. Furthermore, it was found that older adolescents score higher on the somatic problems subscale, on the internal scale and on the total scale of the CBCL, than the younger adolescents did. Dubowitz et al. (1994) also found that the behavioral problems of adolescents increased with age. One possible explanation of this effect relates to the evolution and change that occur during this stage. As adolescents become older, they feel a greater desire for freedom and autonomy. This normally demands that one's relationships with their family and environment be readjusted, which could possibly provoke a higher incidence of behavioral problems. Also, grandparent care-givers, as they age, may experience more health problems, worries and even greater family responsibilities, since it becomes increasingly important that they take care of themselves and even, in some cases, of an ill husband or wife. This situation could mean that the grandparents have less time or ability to adjust to and control changes in the behavior of their grandchildren at certain ages. For that reason, these results may reflect difficulty on the part of the grandparents in controlling the behavior of their grandchildren when they reach adolescence (Sánchez, 2000).

As the fourth hypothesis predicted, the results of this study indicate that adolescents whose mothers were substance abusers score higher on measures of external problems as well as on measures of total behavioral problems. Other studies of the extended family (Benedict et al., 1996; Burnette, 1999; Johnson, 2002; Shapiro et al., 2001) also indicate that the biological parents' problems elicit an influence over the manifestation of behavioral problems in their children. Behavioral problems are greater, for example, for adolescents whose parents consumed drugs or were incarcerated, and above all, who suffered some form of psychopathology. Benedict et al. (1996) suggest that the children of substance abusing parents live in an environment charged with tension, violence and aggression, which influences their subsequent development because they acquire inadequate behavioral habits through their relationships with their parents.

Although it was also expected that active abuse suffered by the children, their having been placed at some point in an orphanage or children's home, and the time they spent there would correlate with a higher incidence of behavioral problems in adolescents raised by their grandparents, the results that were obtained diverge from that hypothesis. This may be due to the fact that in this study, very few of the children had spent time in an orphanage or children's home, and that those who had spent only a brief period of time there. This could explain why no relationships were found between those variables and behavioural problems. In other research studies of adolescents and care-givers, no relationship was found between behavioral problems and having suffered abuse either (Fuentes et al., 2004; Groza \& Ryan, 2002).

One limitation of this study has to do with the use of self-report measures to evaluate behavioral problems. The use of questionnaires and self-report in the process of information collection has sometimes been criticized in the field of psychology, primarily because of social desirability effects. However, using self-report measures also offers certain, undeniable advantages. In the case of the CBCL, among its principal advantages is that its effectiveness, reliability and validity have all been tested. Also, it is widely used, and is very well adapted to obtain the type of information that was necessary to this study.

Another possible limitation has to do with the limited generalizability of the results, since this study was carried out using a sample from a specific, geographic region. Nevertheless, although the study was conducted in a specific geographic area and no control group was utilized, we should keep in mind how highly these results coincide with the results of other studies of adolescents in the custody of their relatives (Dubowitz et al., 1993; Heflinger et al., 2000; Keller et al., 2001; Starr et al., 1999), as well as with the results of other studies of adolescents in other types of care (Fuentes et al., 2004; Groza \& Ryan, 2002).

One contribution made by this study that is worth mentioning is that it was a first attempt to approach this topic, given that no study of behavioural problems in adolescents 
raised by their grandparents had ever been conducted in Spain previously. We also consider it relevant to mention that the researchers themselves collected all the data through direct contact with the families participating in the study.

Last, it would be interesting to complete the data from this study with data collected from the adolescents themselves about their own behavioral problems, since there is a test equivalent to the CBCL, called the YSR, that would easily allow for such a comparison.

As a general conclusion, the data from this study suggests an image of normalcy for the behavior of adolescents raised by their grandparents, which could contribute to changing the pathological emphasis that some studies have placed on children raised in alternative kinds of protection in the past.

\section{References}

Achenbach, T. M. (1991). Manual for the Child Behavior Checklist/4-18 and 1991 CBCL Profile. Burlington, VT: University of Vermont.

Achenbach, T. M. (2001). Manual for the ASEBA school: Age form and profile. Burlington, VT: University of Vermont.

Amorós, P., \& Palacios. J. (2004). Acogimiento familiar. Madrid: Alianza Editorial.

Beeman, S. K., Kim, H., \& Bullerdick, S. K. (2000). Factors affecting placement of children in kinship and non kinship foster care. Children and Youth Services Review, 22(1), 37-54.

Benedict, M. I., Zuravin, S. y Stallings, R. Y. (1996). Adult functioning of children who lived in kin versus nonrelative family foster homes. Child Welfare, 75, 529-549.

Bernedo, I. M. (2004). Adolescentes acogidos por sus abuelos: Relaciones familiares y problemas de conducta. Málaga: Publicaciones de la Universidad de Málaga.

Berrick, J. D. (1998). When children can not remain home: foster family care and kinship care: The future of children. Protecting Children from Abuse and Neglect, 8, 72 - 87.

Berube, R. L., \& Achenbach, T. M. (2001). Bibliography of published studies using ASEBA instruments. Burlington, VT: University of Vermont.

Brodzinsky, D. (1990). A stress and coping model of adoption adjustment. En D. Brodzinsky \& D. Schechter (Eds.), The psychology of adoption (pp. 3-24). New York: Oxford University Press.

Bryson, K., \& Casper, L. (1999). Coresident grandparents and grandchildren. Census Bureau. Current population reports. Special studies. US. Department of Commerce, Economics and Statistics Administration, 1-10 (www.census.gov).

Burnette, D. (1999). Social relationships of Latino grandparent caregivers:.A role theory perspective. The Gerontologist, 39(1), 49-58.

Caputo, R. K. (2001). Depression and health among grandmothers co-residing with grandchildren in two cohorts of women. Family in Society: The Journal of Contemporary Human Services, 82, 473-483.
Dubowitz, H., Feigelman, S., Harrington, D., Starr, R., Zuravin, S., \& Sawyer, R. (1994). Children in kinship care: how do they fare? Children and Youth Services Review, 16 (1/2), 85-106.

Dubowitz, H., Zuravin, S., Starr, R. H., Feigelman, S. y Harrington, D. (1993). Behavior problems of children in kinship care. Journal Developmental and Behavioral Pedriatric, 14(6), 386-393.

Everett, J. E. (1995). Relative foster care: an emerging trend in foster care placement policy and practice. Smith College in Social Work, 65(3), 239-254.

Fernández del Valle, J., Álvarez-Baz, E., \& Bravo, A. (2002). Acogimiento en familia extensa. Perfil descriptivo y evaluación de necesidades en una muestra del Principado de Asturias. Bienestar y Protección Infantil, 1(1), 33-55.

Fuentes, M. J., Fernández, M., \& Bernedo, I. M. (2004). Problemas de conducta, evaluados con CBCL, en adolescentes adoptados españoles. Análisis y Modificación de Conducta, 133(30), 663691.

Ge, X., Conger, R., Cadoret, R., Neiderhiser, J., Yates, W., Troughton, E., \& Stewart, M. (1996). The developmental interface between nature and nurture: a mutual influence model of child antisocial behavior and parent behavior. Developmental Psychology, 32, 574-589.

Gibbs, P.,\& Müller, U. (2000). Kinship foster care: Moving to the mainstream controversy, policy, and outcomes. Adoption Quarterly, 4(2), 57-87.

Groza, V., \& Ryan, S. D. (2002). Pre-adoption stress and its association with child behavior in domestic special needs and international adoptions. Psychoneuroendocrinology, 27, 181197.

Heflinger, C. A., Simpkins, C. G., \& Combs-Orme, T. (2000). Using the CBCL to determine the clinical status of children in state custody. Children and Youth Services Review, 22(1), 55-73.

Iglehart, A. P. (1994). Kinship foster care: placement, service, and outcome issues. Children and Youth Services Review, 16(1/2), 107-122.

Johnson, D.E. (2002). Adoption and the effect on children's development. Early Human Development, 68, 39-54.

Keefer, B., \& Shooler, J. E. (2000). Kinship foster care and adoption: Telling the truth when it's "all in the family". In B. Keefer \& J. E. Shooler (Eds.), Telling the truth to your adopted or foster child: Making sense of the past (pp. 153-163). London: Bergin and Garvey.

Keller, T. E., Wetherbee, K., Le Prohn, N. S., Payne, V., Sim, K., \& Lamont, E. R. (2001). Competencies and problems behavior of children in family foster care: variations by kinship placement status and race. Children and Youth Services Review, 23(12), 915-940.

Kolomer, S. (2000). Kinship foster care and its impact on grandmather caregivers. Journal of Gerontological Social Work, 33(3), 85-102.

Landsverk, J., Davis, I., Ganger, W., Newton, R., \& Johnson, I. (1996). Impact of children psychosocial functioning on reunification from out-of-home placement. Children and Youth Services Review, 18(4/5), 447-462. 
Lumbreras, H., Fuentes, M. J., \& Bernedo, I. M. (2005). Perfil descriptivo de los acogimientos con familia extensa de la Provincia de Málaga. Revista de Psicología Social Aplicada, 15(1), 93-117.

Marchand, H., \& Meulenbergs, W. (1999). Working with family complexy-supporting the network. En R. Greeff (Ed.), Fostering kinship. An international perspective on kinship foster care (pp. 99-112). London: Ashgate Publishing Limited.

Phillips, S., \& Bloom, B. (1998). In whose best interest? The impact of changing public policy on relatives caring for children with incarcerated parents. Child Welfare, 77(5), 531-541.

Pinderhughes, E. (1998). Short term placement outcomes for children adopted after age five. Children and Youth Services Review, 20(3), 223-249.

Reynolds, C. R., \& Kamphaus, R. W. (1992). Behabiour assessment system for Children. Parent Rating Scales. Cicle Pines, M.N.: American Guidance Service.

Sánchez, C. (2000). El Acogimiento familiar en familia extensa de los hijos de padres toxicómanos. Guía para familiares acogedores. Madrid: Ministerio del Interior, Delegación del Gobierno para el Plan Nacional sobre Drogas.

Seymour, C. (1998). Children with parents in prison.: Child welfare policy, program, and practice issues. Child Welfare, 7, 469-494.

Shapiro, V. B., Shapiro, J. R., \& Paret, I. H. (2001). Skippedgeneration kinship care. Grandparents and their grandchildren.
En V. B. Shapiro, J. R. Shapiro, \& I. H. Paret (Eds.), Complex adoption and assisted reproductive technology (pp. 125-147). New York: Guilford Press.

Shore, N., Sim, K., Le Prohn, N., \& Keller, T. (2002). Foster parent and teacher assessments of youth in kinship and non-kinship foster care placements: are behaviors perceived differently across settings? Children and Youth Services Review, 24(1/2), 15-35.

Starr, R. H., Dubowitz, H., Harrington, D., \& Feigelman, S. (1999). Behavior problems of teens in kinship care. Cross-informant reports. En R. L. Hegar, \& M. Scannapieco (Eds.), Kinship foster care: Policy, practice and research (pp. 193-207). New York: Oxford University Press.

Verhulst, F., Althaus, M., \& Versluis-Den Bieman, H. (1990). Problem behavior in international adoptees II. An epidemiological study. Journal American Academy on Child and Adolescent Psychiatry, 29(1), 104-111.

Villalba, C.,\& Sánchez, C. (2000). El acogimiento en familia extensa, un recurso normalizado del sistema de protección. Madrid: Ministerio de Trabajo y Asuntos Sociales.

Received April 19, 2006 Revision received April 1, 2008 Acepted April 12, 2008 